\title{
PERFIL ECONÓMICO DEL MERCADO DE RESIDUOS SÓLIDOS: UN ESTUDIO DE CASO EN CUIABÁ/VÁRZEA GRANDE (BRASIL)
}

\author{
Perfil Econômico do Mercado de Resíduos Sólidos: Um Estudo de Caso em Cuiabá e \\ Várzea Grande (Brasil) \\ Hélde Domingos ${ }^{1}$ \\ Alexandre Magno de Melo Faria ${ }^{2}$ \\ Dilamar Dallemole ${ }^{3}$ \\ José Ramos Pires Manso 4
}

Resumen: La coyuntura socio ambiental y urbana de los municipios brasileños tiene como principal desafío la gestión ambiental en su espacio. Por medio de una investigación en el campo y utilizando estadística descriptiva, fue realizada una caracterización del perfil económico de las empresas de residuos sólidos en Cuiabá y Várzea Grande (Brasil). Los resultados indican que el sector fue responsable por el reciclaje de un $30,3 \%$ de los residuos en estos municipios brasileños en el año de 2010, sin que el Gobierno haya ayudado las firmas con políticas económicas. Las inversiones totales privadas llegaron a 1,2 millones de reales, generando empleos y renta en la economía local, en los sectores comercial, industrial y cooperativo. El mercado de reciclaje es parte estratégica hacia el desafío de la modernización en la gestión de los residuos sólidos. La creación de políticas públicas e incentivos fiscales para el sector productivo es un costo de oportunidad que puede apalancar las tasas de reciclaje. El trabajo proporciona importantes aspectos sociales y económicos de la gestión de los residuos sólidos en centros urbanos.

Palabras-clave: Medio ambiente, reciclaje, residuos sólidos.

Abstract: The environmental and urban context of the Brazilian municipalities have the challenge of environmental management in their space. Through field research and statistic was characterized the economic profile of the solid waste companies in Cuiaba and Várzea Grande in Mato Grosso. The results showed that the sector was responsible for $30.3 \%$ of waste, without assistance from the government. Private investment was 1.2 million, generating employment and income into three segments "commercial", "industrial" and "cooperative." The recycling market is strategic to the challenge of modernization of solid waste management. The creation of public policies and tax incentives for the sector is the opportunity cost of leveraging the recycling production adjusted structure installed. The work provides important socioeconomic and MSW management aspects in urban spaces.

Keywords: Environment, recycling, solid waste.

JEL: Q53

\section{INTRODUCCIÓN}

La producción de residuos sólidos urbanos (RSU) crea varios problemas a la sociedad. Se cree que el nivel diverso de consumo de bienes en la

\footnotetext{
${ }^{1}$ Economista. Doctorando en Economía Aplicada por la Universidad da Beira Interior, Portugal. E-mail: helde@ubi.pt

2 Economista. Doctor en Desarrollo Sostenible por el Núcleo de Altos Estudios Amazónicos (NAEA) de la Universidad Federal de Pará (UFPA), Brasil. Profesor en la Facultad de Economía de la Universidad Federal de Mato Grosso (UFMT). E-mail: dr.melofaria@gmail.com.

${ }^{3}$ Economista. Doctor en Ciencias Agrarias por la Universidad Federal Rural de la Amazonía (UFRA), Brasil. Profesor en la Facultad de Economía de la Universidad Federal de Mato Grosso (UFMT). E-mail: ddallemole@gmail.com

${ }^{4}$ Economista. Profesor Catedrático de la Universidad da Beira Interior, Portugal. E-mail: pmanso@ubi.pt
} 
economía es responsable del empeoramiento de la producción de RSU que se ha reflejado en la actual situación del medio ambiente urbano (Strob, 2009). Por lo tanto, el principal reto de los municipios brasileños es encontrar una solución a corto y mediano plazo, para adaptarse a los requisitos de la Política Nacional de Residuos Sólidos (PNRS), que tenía el año 2014 como fecha límite para su implantación. Los estados y municipios deberían programar la modernización de la gestión de RSU en sus áreas, priorizando el reciclaje de residuos y desactivar los vertederos en el país (MMA, 2010).

La modernización de la gestión de los RSU, como el recojo selectivo de basura, es una importante política pública que debería ser estimulada que, en conjunto con actividades de recuperación de los residuos, podría fomentar la rebaja de generación de RSU inservibles y la valoración de los materiales reciclables. Estas actividades implican selección, limpieza, prensado y/o empaque de materiales que después de estos pasos, se encuentran disponibles para ser transformados en nuevas materias primas (Freitas, 2007). Las organizaciones de recojo de basura han sido responsables por un $13 \%$ de las materias primas suministradas a las industrias de reciclaje en Brasil (MTE, 2006). Así, la economía de mercado ya ha explorado los RSU, donde el capital comercial ubicado entre el recojo y las industrias ha contribuido hacia la consolidación del mercado de residuos sólidos en Brasil (Strob, 2009).

Al nivel local, el índice de crecimiento poblacional de Cuiabá y Várzea Grande (Brasil) ha sido de 1,67\% desde 1991 hasta 2010, mientras el volumen de residuos sólidos ha crecido a un $4,60 \%$ en el mismo periodo (Domingos, 2011). La estructura de recojo de basura ha sido impactada tras esos cambios en el aglomerado urbano de Cuiabá/Várzea Grande (AGLURB) ${ }^{5}$ que, en conjunto con la deposición desordenada, viene generado una incapacidad de mantener una gestión eficiente de RSU en aquellas ciudades. Ambos municipios tienen una alta densidad poblacional, y esto tiene un impacto directo en las políticas públicas adoptadas por los gobiernos locales, que generalmente adoptan soluciones distintas en cada ciudad, impidiendo un sinergismo en las soluciones que deberían ser conjuntas (Werle et al., 1995; Cuiabá, 2007).

En este contexto, el desafío de este trabajo es hacer un ejercicio de reflexión bajo las actuales condiciones estructurales del sector productivo de residuos reciclables en Cuiabá/Várzea Grande, teniendo como objetivo principal la caracterización del perfil económico del mercado de papel, cartón, plástico y aluminio. Además, intentará conocer los principales impactos de la estructura productiva en la capacidad de recojo y reciclaje de residuos sólidos.

El artículo está organizado de la siguiente manera: la sección 2 empieza con una breve descripción general de los aspectos históricos del aglomerado urbano, su ambiente económico, social y ambiental. La sección 3 presenta una revisión de literatura. En la sección 4 está la metodología, en la sección 5 están los resultados y la sección 6 están las conclusiones.

\footnotetext{
${ }^{5}$ La creación del aglomerado urbano Cuiabá/Várzea Grande ocurrió por la Ley Complementar Estadual no 28, de 1993, y fue dispuesta por la Ley Complementar Estadual no 83, de 2001. Después, en Mayo de 2009, fue promulgada una nueva Ley Complementar n 359, creando una Región Metropolitana de la Cuenca del Río Cuiabá, abarcando otros municipios (SMDU, 2010).
} 


\section{CARACTERIZACIÓN GENERAL}

\subsection{Aspectos Históricos del AGLURB}

La conurbación entre los municipios de Cuiabá, capital de Mato Grosso y el municipio vecino Várzea Grande, acentuó el flujo migratorio hacia la región Centro-Oeste de Brasil en la década de 1960. En esta fecha el gobierno central entendió que la capital de Mato Grosso era estratégica hacia la ocupación de la Amazonía Sur brasileña. Hubo un espesamiento poblacional en la región de los municipios Cuiabá y Várzea Grande, que hacen frontera por el río Cuiabá (Faria et al., 2009; Cuiabá, 2007).

En el período entre 1960 y 1992, los problemas generados por el descarte de basura ya eran relevantes en el AGLURB, especialmente la disposición en el relleno sanitario, que ya estaba agotado en 1982. Hasta el 1987 la basura era comprimida sin ningún tratamiento y depositada en capas en el relleno sanitario. En 1988 el problema empeoró, puesto que la basura dejó de ser comprimida antes de ser depositada. No se sabe los motivos de esta última acción. Desde el 1988, la basura fue echada directamente en el piso de forma aleatoria y sin tratamientos especiales para contener o minimizar un posible daño al medio ambiente. El relleno sanitario pasó a ser caracterizado como un vertedero, contaminando el suelo y las aguas subterráneas, incluso un arroyo llamado Ribeirão do Lipa, que corre a través de varios barrios de la capital hasta su desembocadura en el río Cuiabá, un afluente del río Paraguay y uno de los ríos más importantes de la cuenca Norte del Pantanal (Röper, 1996).

Sólo en 1996 el ayuntamiento de Cuiabá firmó un contrato con el Banco Mundial y fueron invertidos recursos externos en la creación del relleno sanitario. Sin embargo, el nuevo sitio de almacenamiento no garantizó el proceso de reciclaje. Sólo un 5\% del material fue recuperado entre1996 y 2010, cuando el relleno había agotado su capacidad de almacenamiento. Desde esta fecha, el relleno está funcionando en régimen de emergencia. A finales de 2012 los trabajos de recuperación de materiales en el relleno sanitario fueron suspendidos. Cómo sólo un $5 \%$ del material es reciclado, el mercado de reciclaje podría expandir el ciclo de vida del relleno se hubiese una expansión del proceso de recuperación de materiales (Carvalho e Silva, 2011).

En situación similar estaba el municipio de Várzea Grande en el mismo periodo. La causa principal también fue la ausencia de una estructura de recojo y disposición final de los residuos, donde empresas públicas y privadas estaban almacenando sus desechos en sitios ilegales. Tales sitios se constituían en "micro vertederos" donde estaban tirados todo tipo de materiales, cómo neumáticos usados, chatarra de metales y residuos domésticos (Werle et al., 1995). En 2011 este cuadro aún no había cambiado, sino había empeorado (Carvalho e Silva, 2011).

Actualmente, hay una esperanza positiva de cambio en el escenario social y ambiental del AGLURB. La Política Nacional de Residuos Sólidos obliga a los poderes locales, al sector productivo, al gobierno central y a la 
población a tener responsabilidad sobre la generación de residuos, el recojo y su almacenamiento seguro (MMA, 2010). Con una economía dinámica y diversificada $^{6}$, el AGLURB generó 198.196,686 toneladas de residuos sólidos urbanos en 2010. Cuiabá generó unas 420.855 toneladas por día y Várzea Grande unas 44.584 toneladas por día. Del total de los RSU generados por AGLURB, unas 30,4 mil toneladas corresponden a los residuos de papel y cartón, unas 26,5 mil toneladas a plástico y unas 5,4 mil toneladas a aluminio (Domingos, 2011).

En este contexto, la economía del AGLURB, al generar una cantidad expresiva de RSU reciclable podría crear un importante mercado de materia prima secundaria. Esta es una alternativa para mitigar los problemas con la disposición final de los RSU. Como dijo Waite (1995), además de los beneficios ambientales, se puede tener el ahorro de energía en el reprocesamiento de materiales en comparación con la extracción y producción de la materia prima original y la recuperación de materias primas secundarias. Además, el sector del reciclaje puede generar puestos de trabajo, la reducción de la deposición de los RSU en los rellenos sanitarios, y, como corolario, reducir los costes de recogida y los impactos ambientales por la desviación de materiales reciclables del vertedero.

\section{REVISIÓN DE LA LITERATURA}

Según Daly (1991), uno de los factores de producción es la naturaleza, y este factor viene siendo cada vez más escaso en el proceso de producción. La preocupación mundial por los problemas ambientales, derivados del consumo, ha traído la urgencia del debate del conflicto entre la economía y el medio ambiente (Alier, 2007). Este conflicto como expresión de la emergencia ambiental llevó a la construcción y a la formulación del concepto de "desarrollo sostenible", preocupado principalmente de los problemas de la sociedad, el medio ambiente, la economía y las perspectivas de las generaciones futuras (Sobrinho et al., 2009).

En este sentido, Altvater (1995) dice que los recursos naturales que se utilizaban en el proceso de desarrollo, no estarían de nuevo disponibles para nuevas estrategias de desarrollo. Es decir, el desarrollo y el medio ambiente están en una relación de intercambio, actividades económicas transforman el medio ambiente y una vez cambiado, el nuevo entorno es una restricción externa al desarrollo económico y social.

Teniendo en cuenta los aspectos descritos y partiendo de la perspectiva de la economía ecológica, se construyen las primeras preguntas. ¿Cuál sería el tamaño del subsistema económico en relación con el total de los ecosistemas? ¿La magnitud de este subsistema se puede conseguir? ¿O cuál debería ser la escala óptima de la economía en relación con el total de los ecosistemas?

\footnotetext{
${ }^{6}$ El AGLURB es responsable por generar el $26,2 \%$ del producto interno bruto de Mato Grosso. El sector de servicios y el comercio representan un $63 \%$ de la economía local del AGLURB. Sus principales factores productivos son el capital humano y las tecnologías de información, dado que los servicios financieros, la educación y formación profesional, la gobernanza pública, logística y servicios especializados representan la mayor parcela del esforzó social (Faria et al., 2009).
} 
Estos problemas no parecen estar bien ordenados en la economía dominante, donde la maximización de la productividad de los factores está bien desarrollada. Pero la maximización sólo se produce a través del uso de tecnologías que tiene un uso intensivo de los recursos naturales, causando el agotamiento de la productividad de estos recursos. Sin embargo, en principio, una solución al problema sería limitar la escala humana de uso de los recursos naturales, aunque no sea el óptimo, pero que no exceda la capacidad de carga de los ecosistemas (Daly, 1991).

Sin embargo, los debates sobre las cuestiones ambientales sólo ganaron fuerza a través de la publicación de varios estudios desde la década de 1970. A partir de ese período se destaca la contribución de otros economistas ecológicos europeos como Renné Passet y Ignacy Sachs, este último introduciendo en su ordenamiento el concepto de eco-desarrollo. Además, Roefie Hueting en los Países Bajos, Cristian Leipert en Alemania y José Manuel-Nareda en España contribuyeron con el debate económico-ecológico (Alier, 2007). La primera conferencia mundial sobre los economistas ecológicos, celebrada en Washington DC en 1990 (Constanza, 1991 apud. Alier, 2007) dio lugar a un libro que se definió el campo conceptual de la economía ecológica como "la ciencia y la gestión de la sostenibilidad".

Pero, añadiendo el debate energético y material e involucrando este debate con los patrones de crecimiento económico, la contribución más genial es de Nicholas Georgescu-Roegen considerado hoy como el gran precursor del debate sobre el tema (Cechin, 2010). Mientras demuestra la fragilidad del análisis ortodoxo económico, Georgescu-Roegen no cree en un sistema circular y lineal, sino complejo y entrópico. El reciclaje absoluto no existe y la humanidad está destinada al fracaso colectivo, en función de la presencia de la entropía en todos los procesos económicos. Para postergar la ruina social, sería necesario reducir drásticamente el consumo material y energético, combinado con altas tasas de reciclaje. Aún sin resolver el problema subyacente, que es la entropía, el reciclaje podría contener parte de la pérdida de calidad energética y material.

\section{METODOLOGÍA}

En el desarrollo de esta investigación, fueron hallados diversos trabajos que hacen la caracterización de los aspectos técnicos de los rellenos sanitarios en Brasil. Sin embargo, en Brasil y otros países, aún no hay una metodología estandarizada hacia la investigación de problemas ambientales involucrados con la economía. Así, las investigaciones ad hoc surgen como una propuesta de trabajo, que generan informaciones básicas en el intercambio de la economía con los sistemas ecológicos (Carneiro, 2006), que pueden suministrar datos y proposiciones a nuevas y más estructuradas investigaciones.

Debido a la gravimetría y heterogeneidad de los materiales sólidos generados en el AGLURB, fue necesario elegir un grupo de empresas que 
trabajan con materiales específicos. Por lo tanto, el estudio incluyó sólo las empresas que venden $y / 0$ industrializan y/o reutilizan materiales reciclables que tienen una gran presencia en los RSU del AGLURB, en sintonía con la literatura que normalmente trabaja en este ámbito de aplicación (IPEA, 2010). En este caso particular, fueron seleccionadas empresas que trabajan con reciclaje de papel y cartón, plástico y metales. Para el grupo de empresas que trabajan con "metales", la investigación fue restringida solamente al grupo de no ferrosos (como latas de aluminio y otros objetos que suelen surgir del recojo de agentes de colección).

Los datos de investigación fueron obtenidos mediante cuestionarios aplicados entre mayo de 2010 y febrero de 2011. El universo de empresas formales o agentes de reciclaje llegaban a 34 empresas en AGLURB. Sin embargo, debido a la falta de información sobre las características de la estructura productiva de las empresas, se definió el cuestionario para toda la población. Después de la identificación, se aplicaron cuestionarios a 22 firmas; una firma se negó a contestar y 11 no estaban en operación.

\section{RESULTADOS}

El AGLURB tiene un recojo selectivo informal realizado por trabajadores autónomos, a partir de viviendas, del comercio en general, en las industrias y en el sector público. El material recogido atiende una demanda creciente de RSU de papel, cartón, plástico y aluminio. El recojo informal es realizado antes del recojo oficial por los ayuntamientos. De esta forma, el recojo informal reduce los costes de gestión de los RSU por los ayuntamientos, pues evita que toneladas de materiales sean cargados, transportados y almacenados por el sistema público de recolección de RSU. La sistematización de generación, destino y comercialización es demostrada en la Figura 1.

Figura 1: Sistematización de generación, destino y comercialización de RSU en el AGLURBFuente

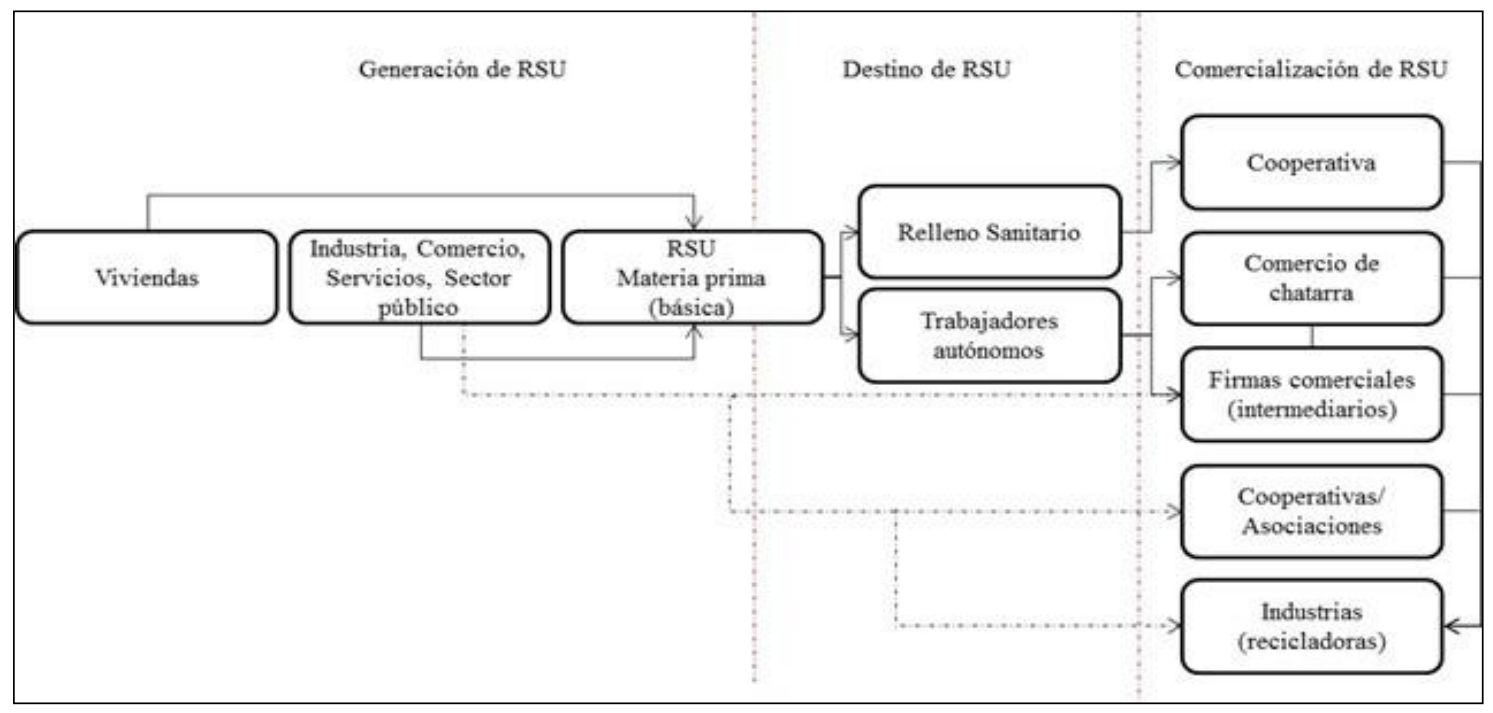

Fuente: Elaboración propia. 
La investigación identificó las condiciones operacionales de esta estructura productiva de reciclaje, cuyas empresas en funcionamiento tienen en promedio 12,27 años de actividad, siendo observado extremos de empresas jóvenes con apenas tres años de vida y empresas con 42 años de actividad. Por supuesto, la madurez de una empresa es un indicador de experiencia de mercado y en esta investigación, las más antiguas tuvieron los mejores indicadores de estructura, puesto que presentaron mayores importes de capital asignados en maquinaria y equipo. En la Tabla 1 se presentan los datos de tiempo de actividad empresarial de la rama de reciclaje en Cuiabá y Várzea Grande.

Tabla 1: Tiempo de instalación de las empresas en el AGLURB

\begin{tabular}{ccc}
\hline $\begin{array}{c}\text { Tiempo de actividad } \\
\text { (en años) }\end{array}$ & № empresas & $\%$ \\
\hline $0-5$ & 5 & 22,73 \\
$6-10$ & 4 & 18,18 \\
$11-20$ & 10 & 45,45 \\
$21-30$ & 2 & 9,09 \\
$>30$ & 1 & 4,55 \\
\hline Total & 22 & 100
\end{tabular}

Fuente: Datos de la investigación, 2010/2011.

Específicamente en la rama industrial (excluyéndose las ramas comerciales y las cooperativas/asociaciones), las firmas jóvenes presentan una mejor estructura técnica, con asignación de maquinaria y equipo. Se cree que esta condición es explicada porque estas empresas ya nacen con acceso à la tecnología actualizada quemando etapas en la evolución tecnológica. Además, las empresas maduras tienen capital inmovilizado que necesita ser capitalizado antes de ser reemplazado.

Durante el período de la investigación, fue observado que el sector de los RSU generó un total de 484 puestos de trabajo, que se distribuye entre las ramas comerciales, industriales y cooperativas/asociaciones. El mayor porcentaje de puestos de trabajo se produjo en el sector comercial, con un $40,8 \%$ de los puestos de trabajo, seguido de las asociaciones/cooperativas con un $33,06 \%$ y las actividades industriales con un $26,86 \%$ de los empleos generados en el sector, conforme la Tabla 2.

De acuerdo con el Informe Anual de Informaciones Sociales ${ }^{7}$ del Ministerio de Trabajo y Empleo (MTE) de Brasil, en 2010 había 202 empleados formales asignados en la producción de residuos sólidos del AGLURB, distribuidos en 18 propiedades en los segmentos de recuperación de chatarra de aluminio; recuperación de papel y cartón; y plástico. Estas declaraciones presentan divergencia de los datos empíricos, excluyendo las cooperativas y asociaciones. La industria recicladora y las empresas comerciales contaban con 324 empleados observados en la investigación. Así, el estudio de campo

\footnotetext{
${ }^{7}$ Relatório Anual de Informações Sociais (RAIS), en portugués.
} 
identificó 122 puestos de trabajo más allá que en la base de datos oficiales. Esto podría confirmar la existencia de trabajo informal en las empresas.

Tabla 2: Empleos directos en el sector de reciclaje de RSU en el AGLURB

\begin{tabular}{lcc} 
Ramas del sector de reciclaje & Empleos directos & $\%$ \\
\hline Comercial & 194 & 40,08 \\
Cooperativas/Asociaciones & 160 & 33,06 \\
Industria recicladora & 130 & 26,86 \\
\hline Total General & 484 & 100
\end{tabular}

Fuente: Datos de la investigación, 2010/2011.

Los ingresos promedios de los empleados del sector de reciclados eran de $\mathrm{R} \$ 749,86$ durante el período de la investigación, lo que representa una hoja de pagos equivalente a aproximadamente $R \$ 362$ mil mensuales. El salario mínimo en Brasil en el momento de la investigación era de $R \$ 510,00$. Los salarios del sector estaban alrededor de un $47 \%$ por encima del mínimo y representan un importe aproximado de 4,7 millones de reales anuales distribuido a los empleados de la industria del reciclaje en AGLURB.

La rotación de los empleados del sector es muy relevante para las empresas, generando elevados costes con contribuciones sociales de los trabajadores. En alrededor de un $45 \%$ de las empresas del AGLURB, la rotación alcanza porcentajes arriba de un $20 \%$ del cuadro de empleados. Un $23 \%$ de la rotación está entre10\% y $20 \%$ del cuadro de empleados. Los principales factores citados por las empresas que generan la elevada rotación de empleados son (1) reducida capacitación profesional de los empleados, (2) baja educación formal, (3) ausencia de compromiso de los empleados con la empresa, (4) uso de alcohol y drogas, y (5) los empleados tienen compromiso solamente hasta seis meses de trabajo, fecha que garantizaba el derecho de acceso al seguro de desempleo. El porcentaje de rotación de trabajadores en las empresas de reciclaje de RSU en el AGLURB está disponible en la Tabla 3.

Es posible relativizar la posición de las empresas en la rotación de los empleados. El promedio salarial en el periodo analizado fue de 1,47 sueldos mínimos. En esta realidad es difícil crear fuertes relaciones contractuales entre empleadores y trabajadores. De este modo, el trabajador tiende a moverse entre las empresas a medida que alcanzan los mismos salarios en otros sectores de la economía. No hay incentivos importantes para permanecer en el sector de reciclados. Por el contrario, desde el punto de vista empresarial, los trabajadores son reemplazables debido a la falta de capacitación y la ausencia de contractos formales, que facilita la interrupción contractual de ambos lados.

Tabla 3: Rotación del personal empleado en el sector de reciclaje

\begin{tabular}{cccc}
\hline $\begin{array}{c}\text { Baja } \\
\text { (abajo de 10\% } \\
\text { al año) }\end{array}$ & $\begin{array}{c}\text { Promedia } \\
(\mathbf{1 0 \%} \text { a 20\% al año) }\end{array}$ & $\begin{array}{c}\text { Alta } \\
\text { (arriba de 20\% al } \\
\text { año) }\end{array}$ & Total \\
\hline 7 & 5 & 10 & 22 \\
\hline $31,82 \%$ & $22,73 \%$ & $45,45 \%$ & $100 \%$ \\
\hline
\end{tabular}

Fuente: Datos de la investigación, 2010/2011. 
Cabe señalar que una de las demandas de los empresarios está relacionada con la falta de mano de obra calificada, tanto en la actividad relacionada con los procesos operativos, así como en las actividades administrativas. Una alternativa sería ofrecer la capacitación del personal que podría aumentar la productividad del trabajo, mayores ingresos para los trabajadores y una mayor adherencia en las empresas, reduciendo la rotación.

El sector de reciclaje en el AGLURB representó 391 empleos directamente relacionados con la producción y otros 93 puestos de trabajo burocráticos en las empresas, lo que representa el $81 \%$ de los puestos de trabajo asignados directamente en la producción, y el 19\% destinado a las actividades administrativas. Debería haber una planificación de la capacitación técnica respetando esa composición orgánica del trabajo. Las empresas también deberían tener algún control bajo la formación profesional y no esperar solamente una política pública para resolver la carencia de mano de obra adaptada a las condiciones productivas.

La estructura productiva del sector cuenta con activos económicos asignados en maquinaria y equipo. La inversión total en las tecnologías del sector para ayudar al trabajo de producción es de 5,5 millones de reales, distribuidos en las tres ramas de actividad, donde el $13,6 \%$ de las empresas tiene inversiones en bienes de capital superiores a 1,2 millones de reales, en el $9,1 \%$ de las empresas las inversiones varían entre 501.000 y un millón de reales, un $22,7 \%$ tienen inversiones hasta 500 mil reales y un $54,5 \%$ de las empresas tienen activos de capital inferiores a 100 mil reales (ver Tabla 4).

Los datos indican que la industria recicladora no es generadora de innovación tecnológica, por lo tanto, el mercado sólo realiza el preprocesamiento de materia prima recogida de RSU. Los bienes de capital del sector se refieren a prensas, molinos, trituradoras, extrusoras, pulidores, máquina policorte, filetadora, triturador, carretillas elevadoras, tractores, carpetas, grúas, secadoras y camiones.

Tabla 4: Valores de los bienes de capital del sector de RSU en el AGLURB

\begin{tabular}{lcc}
\hline Valores de bienes de capital (en Reales R\$) & № empresas & $\%$ \\
\hline Hasta 100.000 & 12 & 54,5 \\
De 101.000 a 500.000 & 5 & 22,7 \\
De 501.000 a 1.000 .000 & 2 & 9,1 \\
$>1.000 .000$ & 3 & 13,6 \\
\hline Total & 22 & 100,0 \\
\hline
\end{tabular}

Fuente: Datos de la investigación, 2010/2011.

Al analizar la segmentación de las empresas por tipo de material, los datos indican que un $54,55 \%$ de las empresas trabajan con más de dos tipos de materiales reciclables, los demás se distribuyen entre las empresas que se especializan en un solo tipo de material reciclable (ver Tabla 5). Los recolectores son inseparables de los tres tipos de residuos investigados, lo que sugiere que existe una fuerte dependencia de las empresas demandantes de 
RSU en relación con los proveedores (colectores). Esto es debido al alto coste de desplegar sus propias empresas de logística para organizar el material que está dispuesto de forma fragmentada en el ALGURB. Así, ya que las empresas dependen del trabajo de los recolectores, están obligados a comprar otros tipos de RSU ofrecidos por estos y no sólo un artículo específico.

Con esta conducta, las empresas pueden preservar su fuente de materia prima, por lo que sus proveedores no dejen de ofrecer la materia prima principal. Al mismo tiempo, desincentiva a los recolectores a pasar RSU a los competidores. Esto demuestra el entorno competitivo de los RSU en el mercado e indica la necesidad de remunerar a los trabajadores que están en la base, el recojo autónomo de RSU.

Tabla 5: Empresas en el sector de RSU y actividad por el tipo de material de RSU

\begin{tabular}{lcc}
\hline Actividades por tipo de material de RSU & $\begin{array}{c}\text { No de } \\
\text { empresas }\end{array}$ & $\%$ \\
\hline $\begin{array}{l}\text { Empresas que trabajan con dos o más } \\
\text { componentes de RSU }\end{array}$ & 12 & 54,55 \\
$\begin{array}{l}\text { Empresas que trabajan solamente con } \\
\text { aluminio }\end{array}$ & 7 & 31,82 \\
$\begin{array}{l}\text { Empresas que trabajan solamente con } \\
\text { papel/cartón }\end{array}$ & 2 & 9,09 \\
$\begin{array}{l}\text { Empresas que trabajan solamente con } \\
\text { plástico }\end{array}$ & 1 & 4,55 \\
\hline Total & 22 & 100 \\
\hline
\end{tabular}

Fuente: Datos de la investigación, 2010/2011.

En la primera fase de la comercialización, los principales competidores de los RSU en el AGLURB son las industrias de reciclaje que llegan a demandar un $72,7 \%$ de la materia prima. Los intermediarios llegan a adquirir un $9,1 \%$ de los RSU y el $18,1 \%$ son materias primas secundarias que llegan a la etapa final del proceso de reciclaje y que son adquiridos por mayoristas, minoristas y consumidores.

En el último caso citado, los $18,1 \%$ son comprados por empresas de reciclaje de aluminio y cooperativas que pueden agregar valor a su oferta de productos, incluidos los bienes finales. Por otro lado, en la segunda etapa de la comercialización, las empresas recicladoras de papel/cartón y plástico comercializan material pre-procesado o presionado y/o enfardado con las industrias de reciclaje externas a Mato Grosso. Aquí hay una percepción de qué parcela considerable de los RSU es reciclada total o parcialmente en Mato Grosso, denotando un cierto esfuerzo industrial.

Las empresas del sector de RSU en el AGLURB han reivindicado, de forma sistemática, políticas públicas de apoyo. El principal reclamo de los agentes económicos es la ausencia de crédito para el sector de reciclaje, siendo unánime el deseo de obtener financiamiento para comprar maquinaria, equipos y capital de trabajo. Además, solicitan algún tipo de incentivo fiscal. La investigación indicó que un $95,45 \%$ de las empresas no tuvieron acceso al 
crédito. Solamente una empresa ha adquirido financiación a través de préstamos privados para su capital de trabajo (Tabla 7).

Tabla 6: Principales compradores de materia prima (RSU) en el AGLURB

\begin{tabular}{lcc}
\hline Tipos de Compradores & No de empresas & $\%$ \\
\hline Recicladoras & 16 & 72,7 \\
Intermediarios & 2 & 9,1 \\
Consumidor Final & 1 & 4,5 \\
Mayoristas Estaduales & 1 & 4,5 \\
Minoristas Estaduales & 2 & 9,1 \\
\hline Total & 22 & 100 \\
\hline
\end{tabular}

Fuente: Datos de la investigación, 2010/2011.

Esta imagen contrasta con otros sectores económicos instalados en Mato Grosso, que reciben incentivos fiscales y considerable crédito (Faria et al., 2009). Es posible citar la producción de soja, el cultivo de algodón, productos lácteos, industria de la confección y la industria del mueble, llegando a recortes de impuestos entre 75\% y $100 \%$, dependiendo de la legislación que se ajuste. Así, mientras que otros sectores de la economía de Mato Grosso coexisten con abundancia relativa de incentivos fiscales y crediticios, el sector de la economía de reciclados no tiene el básico de los fundamentos clásicos del apoyo económico. Mientras permanece aislado de los apoyos económicos, el sector de RSU del AGLURB contribuye al Producto Interno Bruto local, con la creación de empleo y sueldos, y proporciona una mejor calidad ambiental en las zonas de mayor densidad poblacional.

La estructura productiva del mercado de RSU en el AGLURB ha reciclado, sin ayuda gubernamental, un $30,3 \%$ de todo el papel/cartón, plástico y aluminio producido como residuos en 2010.

Tabla 7: Acceso al crédito e incentivo fiscal

\begin{tabular}{lcc}
\hline $\begin{array}{c}\text { Empresa recibe apoyo crediticio y } \\
\text { financiero }\end{array}$ & N. empresas & $\%$ \\
\hline Financiación por préstamo & 1 & 4,55 \\
Incentivo fiscal & 0 & 0,00 \\
Ninguno & 21 & 95,45 \\
\hline Total & 22 & 100 \\
\hline
\end{tabular}

Fuente: Datos de la investigación, 2010/2011.

En general, el mercado de RSU generó en 2010 unos 31 millones de reales, de los cuales unos 16,1 millones de reales fueron generados en la base, con la remuneración de los recolectores, que suministraron alrededor de unas 27 toneladas de RSU para las empresas intermediarias en la primera fase de comercialización. En la segunda fase del proceso, fueran añadidos otros 14,9 millones de reales por las empresas comerciales e industriales (véase la Tabla 8). 
Tabla 8: Potencial total de reciclaje en el AGLURB: año 2010

\begin{tabular}{lccccc}
\hline $\begin{array}{l}\text { Potencial de } \\
\text { reciclaje }\end{array}$ & Local & Tonelada & $\begin{array}{c}\text { Fase 1 } \\
(\mathbf{R} \$ \mathbf{)}\end{array}$ & $\begin{array}{c}\text { Fase 2 } \\
(\mathbf{R} \$ \mathbf{)}\end{array}$ & Total \\
\hline RSU reciclados & AGLURB & $27.096,75$ & $16.107 .335,00$ & $14.942 .527,11$ & $31.049 .862,11$ \\
Residuos & AGLURB & $62.471,60$ & $30.231 .343,63$ & $38.848 .317,48$ & $69.079 .661,11$ \\
enterrados & AGLURB & $89.568,34$ & $46.338 .678,63$ & $53.790 .844,59$ & $100.129 .523,22$ \\
\hline Potencial Total
\end{tabular}

Fuente: Datos de la investigación, 2010/2011.

También se estimó el potencial de mercado de los RSU que no se encuentran disponibles de inmediato, que son aquellos materiales que están depositados en el relleno sanitario y los vertederos. El peso total estimado en el relleno/vertederos es de 62,4 mil toneladas, con unas 30,5 mil toneladas de papel y cartón, unas 26,5 mil toneladas de plástico y 5,4 mil toneladas de aluminio. En el caso de que estas 62,4 mil toneladas pudiesen ser recicladas, podrían generar unos 69,0 millones de reales.

$\mathrm{Y}$, si se añaden las 62,4 mil toneladas del relleno/vertederos con las 27,1 mil toneladas recicladas, se tienen unas 89,5 mil toneladas de RSU potencialmente reciclables en 2010 , las cuales se refieren solamente a los tres tipos de materiales investigados. En conjunto, el mercado de los RSU que recicla de manera efectiva junto con el mercado potencial, podría haber generado en 2010 unos 100 millones de reales, según la Tabla 8.

Los datos oficiales de Cuiabá indican que la población de 551.098 habitantes en 2010 generó 153.610 toneladas de RSU, produciendo 420,85 toneladas por día y $278,74 \mathrm{~kg}$ de RSU per cápita al año. Excluyendo los RSU que fueron recogidos antes del sistema oficial del ayuntamiento, para la formación del mercado de reciclaje, el servicio de recojo de estas 153.610 toneladas que fueron enviados al relleno sanitario tuvieron un coste de 16,9 millones de reales para el ayuntamiento. El coste anual por habitante fue de $R \$$ 30,77 solamente para el servicio de recojo. El gasto corriente total del ayuntamiento de Cuiabá alcanzó 899,5 millones de reales. El coste de los RSU alcanzó el 1,88\% del total del gasto municipal. El coste de la gestión de RSU en la capital fue de R\$ 0,11 por kilo/RSU en el año 2010.

En Várzea Grande, los datos oficiales indican que la población de 252.596 habitantes en 2010 generó 44.580 toneladas de RSU, con una producción de 122,15 toneladas por día y 176,50 kg de RSU per cápita al año. Se observa que la producción anual de RSU per cápita en Várzea Grande es $36,68 \%$ más bajo que en Cuiabá, probablemente relacionado con una renta per cápita menor que Cuiabá en 31,90\%. Excluyendo los RSU que no fueron recogidos por el ayuntamiento, el servicio de recojo oficial costó unos 3,6 millones de reales, con un costo per cápita de $R \$ 14,25$ por año, solamente para el servicio de recojo. El gasto total del ayuntamiento alcanzó 275,6 millones de reales y el costo de los RSU alcanzó el 1,31\% del total del gasto municipal. El coste de la gestión de los RSU en Várzea Grande fue de $R \$ 0,08$ por kilo en el 2010. Nótese que en Várzea Grande el costo del manejo de los RSU tanto per cápita como por kilo es inferior a Cuiabá, porque no hay relleno 
sanitario, sino vertederos. Así, en Várzea Grande hay solamente un proceso de eliminación de los residuos a cielo abierto.

Tabla 9: Indicadores de la gestión de RSU en Cuiabá (2010)

\begin{tabular}{lr}
\hline Población de Cuiabá en 2010 (habitantes) & 551.098 \\
Total de RSU recogido en 2010 (toneladas) & $153.612,11$ \\
Generación de RSU por día (toneladas) & 420,85 \\
Generación de RSU por habitante por año (quilos) & 278,74 \\
Coste total de la gestión con RSU en Cuiabá en 2010 & $\mathrm{R} \$ 16.962 .102,37$ \\
Coste de la gestión por habitante & $\mathrm{R} \$ 30,77$ \\
Gastos corrientes del ayuntamiento de Cuiabá en & $\mathrm{R} \$ 899.503 .038,93$ \\
2010 & \\
\% del coste de la gestión de RSU en los gastos totales & $1,88 \%$ \\
del ayuntamiento & $\mathrm{R} \$ 11.051 .572 .000,00$ \\
Producto Interno Bruto (PIB) de Cuiabá en 2010 & $\mathrm{R} \$ 20.053,73$ \\
PIB per cápita & $\mathrm{R} \$ 0,11$ \\
Coste de la gestión de RSU/kilogramo &
\end{tabular}

Fuente: Datos de la investigación (2011); SNIS (2011); IBGE (2013); Sanecap (2011).

Con la agregación de datos de Cuiabá y Várzea Grande, es posible ver que la población de 803.964 habitantes en el 2010 generó 198.190 toneladas de RSU, con una producción de 543,00 toneladas por día y $246,60 \mathrm{~kg}$ de RSU per cápita al año. El servicio oficial de recojo de residuos de los dos ayuntamientos tuvo un coste de 20,5 millones de reales, con un costo per cápita de $R \$ 25,58$ por año, solamente para este servicio. Los costos totales de funcionamiento de los dos municipios fueron de 1.170,0 millones de reales y el costo de los RSU alcanzó el 1,75\% del total del gasto municipal. El coste medio de la gestión de los RSU en AGLURB fue de R\$ 0,10 por kilo en el 2010.

Tabla 10: Indicadores de la gestión de RSU en Várzea Grande (2010)

\begin{tabular}{|c|c|}
\hline Población de Várzea Grande en 2010 (habitantes) & 252.596 \\
\hline Total de RSU recogido en 2010 (toneladas) & $44.584,576$ \\
\hline Generación de RSU por día (toneladas) & 122,15 \\
\hline Generación de RSU por habitante por año (quilos) & 176,50 \\
\hline $\begin{array}{l}\text { Coste total de la gestión con RSU en Várzea Grande } \\
\text { en } 2010\end{array}$ & $\mathrm{R} \$ 3.600 .000,00$ \\
\hline Coste de la gestión por habitante & $R \$ 14,25$ \\
\hline $\begin{array}{l}\text { Gastos corrientes del ayuntamiento de Várzea } \\
\text { Grande en } 2010\end{array}$ & $R \$ 275.670 .481,70$ \\
\hline $\begin{array}{l}\% \text { del coste de la gestión de RSU en los gastos } \\
\text { totales del ayuntamiento }\end{array}$ & $1,31 \%$ \\
\hline $\begin{array}{l}\text { Producto Interno Bruto (PIB) de Várzea Grande en } \\
2010\end{array}$ & $\mathrm{R} \$ 3.449 .446,00$ \\
\hline PIB per cápita & $R \$ 13.655,98$ \\
\hline Coste de la gestión de RSU/kilogramo & $R \$ 0,08$ \\
\hline
\end{tabular}


Como se discutió previamente, y resumido en la Tabla 11, el valor del reciclaje de RSU en el AGLURB alcanzó 31,0 millones de reales en el 2010, sin el apoyo de ningún tipo de instrumento económico de inducir el segmento productivo. El valor añadido por el sector de reciclaje representa un $0,21 \%$ del PIB del AGLURB.

También hay cerca de 69,0 millones de reales en materiales echados en el relleno/vertederos, lo que podría añadir aproximadamente un $0,48 \%$ al valor del PIB del AGLURB si fueran reciclados por las cadenas productivas de plástico, papel y aluminio. Los dos ayuntamientos del AGLURB asignan 20,5 millones de reales para recoger diversos materiales, que alcanzarían al menos unos 69,0 millones de reales si se les consideraba como materia prima secundaria.

Por último, en el caso de que pudiera añadirse el valor de los materiales reciclados y echados en el relleno/vertederos, tendrían alrededor de 100,1 millones de reales en este segmento productivo, que podrían representar hasta un $0,69 \%$ del producto interno bruto del AGLURB. A modo de comparación, el sector agrícola en estos dos municipios representó sólo el $0,45 \%$ del PIB en el 2010. La estructuración de un segmento productivo de reciclados en el AGLURB podría representar un valor más elevado que el sector primario en estos espacios.

Tabla 11: Indicadores de la gestión de RSU en el AGLURB (2010)

Población en 2010 803.694

Total de RSU recogido en 2010 (toneladas)

$198.196,686$

Generación de RSU por día (toneladas) 543,00

Generación de RSU por habitante por año (quilos)

246,60

Coste total de la gestión con RSU en 2010

$\mathrm{R} \$ 20.562 .102,37$

Coste de la gestión por habitante

$\mathrm{R} \$ 25,58$

Gastos corrientes de los ayuntamientos del

AGLURB en 2010

$R \$ 1.175 .173 .520,63$

\% del coste de la gestión de RSU en los gastos

totales de los ayuntamientos

$1,75 \%$

Producto Interno Bruto (PIB) del AGLURB en 2010

$R \$ 14.501 .018 .000,00$

Coste de la gestión de RSU/kilogramo

$\mathrm{R} \$ 0,10$

PIB per cápita

$\mathrm{R} \$ 18.042,96$

Valor de los RSU reciclados en 2010

$31.049 .862,11$

$\%$ de los RSU reciclados en el PIB de 2010

$0,21 \%$

Valor de los RSU potenciales enterrados en 2010

$69.079 .661,11$

$\%$ de los RSU potenciales enterrados en el PIB de

2010

$0,48 \%$

Valor de los RSU potenciales totales en 2010

$100.129 .523,22$

$\%$ de los RSU potenciales totales en el PIB de 2010

$0,69 \%$

Fuente: Datos de la investigación (2011); SNIS (2011); IBGE (2013); Sanecap (2011); Secretaria de Infraestructura del Ayuntamiento de Várzea Grande (2011).

\section{CONCLUSIONES}

La caracterización del perfil económico del mercado de los residuos sólidos en el AGLURB Cuiabá/Várzea Grande, presenta aspectos relevantes 
desde el punto de vista económico y ambiental. Las repercusiones positivas de la estructura productiva de reciclados de este espacio demuestran su contribución en la mitigación de los problemas causados por la inadecuada disposición de los RSU. Incluso, a pesar de la ausencia de ayuda del sector público, el mercado privado de reciclados fue responsable por reciclar un $30,3 \%$ de las chatarras de plástico, aluminio y papel/cartón en estos municipios, con la generación de ingresos, empleos y el ahorro de costes con el mantenimiento del relleno/vertederos.

Por lo tanto, el mercado del reciclaje en el AGLURB puede caracterizarse como una parte estratégica para el reto de la modernización de la gestión de los residuos sólidos. La creación de políticas públicas, como la apertura de incentivos crediticios y fiscales para el sector es el costo de oportunidad de apalancamiento de las tasas de reciclaje, ajustado a la estructura de producción instalada. Sólo con tres tipos de residuos analizados en esta investigación, el valor agregado de los RSU como materia prima secundaria podría superar todo el valor agregado del sector primario local. El estudio tiene limitaciones, pues la temática no fue agotada. Pero, ofrece características importantes del sector, en el aspecto socioeconómico y la gestión de los RSU en el espacio analizado.

\section{AGRADECIMIENTOS}

La investigación tuvo apoyo financiero por medio de una beca de estudios suministrada por la Fundación CAPES, del Ministerio de Educación de Brasil. Especiales saludos también son extendidos al Núcleo de Investigación (NECE) del Departamento de Gestión y Economía de La Universidad de la Beira Interior de Portugal por el apoyo en la elaboración del texto.

\section{REFERENCIAS}

Alier, J. M. (2007) "O ecologismo dos pobres: conflitos ambientais e linguagens de valoração". São Paulo: Contexto

Altvater, E. (1995) "O Preço da Riqueza". Trad. Wolfgang Leo Maar. São Paulo, Editora da Unesp

BRASIL. (2010) "Plano Nacional de Resíduos Sólidos". Ministério do Meio Ambiente (MMA), Brasília - DF

BRASIL. (2010) "Relação Anual de Informações Sociais". Ministério do Trabalho e Emprego (MTE), Brasília-DF

BRASIL. (2010) "Diagnóstico do Manejo de resíduos sólidos urbanos2008". Sistema Nacional de Informações sobre Saneamento-SNIS. Ministério das Cidades. Brasília-DF, Secretaria Nacional de Informações sobre Saneamento 
Carneiro, P. F. N. (2006) "Caracterização e avaliação da potencialidade econômica da coleta seletiva e reciclagem dos resíduos sólidos domiciliares gerados nos municípios de Belém e Ananindeua". Dissertação de mestrado, UFPA. Belém-PA

Carvalho, M.A.E; Silva, I.A.F. Análise Diagnóstica sobre a Gestão dos Resíduos Sólidos: um estudo de caso no aterro sanitário de Cuiabá. VIII Simpósio de Excelência em Gestão e Tecnologia - SEGeT, Resende/RJ, 1921, outubro, 2011.

Cechin, A. (2010) "A natureza como limite da economia: a contribuição de Nicholas Georgescu-Roegen". Ed. SENAC. São Paulo/Edusp. São Paulo-SP

CUIABÁ. (2007) "Súmula de Informações do Município de Cuiabá". Prefeitura Municipal de Cuiabá. Instituto de Planejamento e Desenvolvimento Urbano (IPDU), 18. ${ }^{a}$ ed. $28 p$

CUIABÁ. (2011) "Dados aterro sanitário: composição gravimétrica". Companhia de Saneamento da Capital (SANECAP), Prefeitura de Cuiabá, Cuiabá-MT

Daly, H. E. (1991) "A economia ecológica e o desenvolvimento sustentável". In textos para debate 34. Desktop Publicações Ltda. Rio de janeiro

Domingos, H. A. (2011) "Economia dos Reciclados: Uma análise do mercado de resíduos sólidos no Aglomerado Urbano Cuiabá/Várzea Grande". Dissertação - Mestrado em "Agronegócios e Desenvolvimento Regional". Faculdade de Economia-FE/UFMT, Cuiabá-MT

Faria, A. M. M., Dallemole, D., Lamera, J., Figueiredo, M. G., Leite, S. C. F. (2009) "Análise do Mapeamento e das Políticas para Arranjos Produtivos Locais no Norte e Nordeste do Brasil e dos Impactos dos Grandes Projetos Federais em Estados Nordestinos Selecionados - Unidade da Federação Projeto de Pesquisa - Mato Grosso

Freitas, L. F. S. (2007) "Potencial econômico da reciclagem de resíduos sólidos urbanos na Bahia: uma abordagem insumo-produto". Dissertação de mestrado em Economia regional e do meio ambiente - Universidade Federal da Bahia. Salvador-BA

INSTITUTO BRASILEIRO DE GEOGRAFIA E ESTATÍSTICA-IBGE (2010). "Indicadores de Desenvolvimento Sustentável". Rio de Janeiro-RJ

NSTITUTO BRASILEIRO DE GEOGRAFIA E ESTATÍSTICA-IBGE. (2013) "Censo demográfico 2010". Sitio acessado em abril de 2013. Disponível em <http://www.ibge.gov.br/home/estatistica/populacao/censo2010/calendario.shtm INSTITUTO DE PESQUISA ECONÔMICA APLICADA-IPEA. (2010) "Relatório de Pesquisa - Pesquisa sobre pagamento por serviços ambientais urbanos para gestão de resíduos sólidos". Diretoria de Estudos e Políticas Regionais, Urbanas e Ambientais - Dirur. Brasília-DF

Röper, M. (1996) "Setor Informal e Lixo Urbano: os catadores do lixão de Cuiabá entre a sobrevivência e as políticas ecológicas". In Ambiente -Uma abordagem socioeconômica II. Cadernos do Núcleo de Estudos Rurais e Urbanos - NERU. no 4 EdUFMT, Cuiabá-MT, ISSN 0104-3439 
Sobrinho, N. N., Mota, J. A., Amazonas, M. C. (2009) "Instrumentos Econômicos para a Gestão dos Resíduos Sólidos: potencialidades e perspectivas no Brasil". In VIII ecoeco. Cuiabá-MT

Strob, P. Y. (2009) "Diagnóstico socioambiental do território do lixão municipal de Maceió: cidadania em vida do lixo". In Responsabilidade social das empresas: a contribuição das Universidades. Volume 7. Editora Peirópolis: Instituto Ethos. São Paulo-SP

Waite, R. (1995) "Household waste recycling". London: Earthscan Publications

Werle, H. S., Lazaretti, I., Oliveira, B. (1995) "Uma discussão preliminar da questão dos resíduos sólidos em Cuiabá e Várzea Grande: da produção à deposição". Revista Mato-grossense de geografia, ano 01, ํo 0, Cuiabá-MT 